\title{
Compliance and treatment satisfaction of post menopausal women treated for osteoporosis. Compliance with osteoporosis treatment
}

\author{
Dominique Huas ${ }^{1}$, Françoise Debiais ${ }^{2}$, Francis Blotman ${ }^{3}$, Bernard Cortet ${ }^{4}$, Florence Mercier ${ }^{5}$, Chantal Rousseaux ${ }^{6}$, \\ Véronique Berger ${ }^{6}$, Anne-Françoise Gaudin ${ }^{7}$, François-Emery Cotté ${ }^{7,8^{*}}$
}

\begin{abstract}
Background: Adherence to anti-osteoporosis treatments is poor, exposing treated women to increased fracture risk. Determinants of poor adherence are poorly understood. The study aims to determine physician- and patientrated treatment compliance with osteoporosis treatments and to evaluate factors influencing compliance.

Methods: This was an observational, cross-sectional pharmacoepidemiological study with a randomly-selected sample of 420 GPs, 154 rheumatologists and 110 gynaecologists practicing in France. Investigators included postmenopausal women with a diagnosis of osteoporosis and a treatment initiated in the previous six months. Investigators completed a questionnaire on clinical features, treatments and medical history, and on patient compliance. Patients completed a questionnaire on sociodemographic features, lifestyle, attitudes and knowledge about osteoporosis, treatment compliance, treatment satisfaction and quality of life. Treatment compliance was evaluated with the Morisky Medication-taking Adherence Scale. Variables collected in the questionnaires were evaluated for association with compliance using multivariate logistic regression analysis.
\end{abstract}

Results: 785 women were evaluated. Physicians considered $95.4 \%$ of the sample to be compliant, but only $65.5 \%$ of women considered themselves compliant. The correlation between patient and physician perceptions of compliance was low ( $\kappa: 0.11$ [95\% Cl: 0.06 to 0.16]). Patient-rated compliance was highest for monthly bisphosphonates (79.7\%) and lowest for hormone substitution therapy (50.0\%). Six variables were associated with compliance: treatment administration frequency, perceptions of long-term treatment acceptability, perceptions of health consequences of osteoporosis, perceptions of knowledge about osteoporosis, exercise and mental quality of life.

Conclusion: Compliance to anti-osteoporosis treatments is poor. Reduction of dosing regimen frequency and patient education may be useful ways of improving compliance.

\section{Background}

Anti-osteoporosis treatments such as bisphosphonates, selective oestrogen receptor modulators (SERMs) and strontium ranelate have been demonstrated to reduce significantly the risk of osteoporotic fracture in women with post-menopausal osteoporosis [1]. Nonetheless, the effectiveness of these treatments in routine clinical practice may be compromised by poor treatment adherence. Indeed, a number of studies have reported low

\footnotetext{
* Correspondence: francois-emery.e.cotte@gsk.com

${ }^{7}$ Laboratoire GlaxoSmithKline, Marly le Roi, France

Full list of author information is available at the end of the article
}

compliance or persistence rates, notably with bisphosphonates [2], and others have demonstrated that poor adherence compromises control of fracture risk [3,4].

A number of strategies have been proposed for improving adherence to treatment in post-menopausal osteoporosis, including reduction of dosing frequency, patient education programmes and bone mineral densitometry or other surrogate markers to help patients follow treatment-related changes in bone mass [5]. In order to evaluate the utility of such measures, it is important to acquire data on how patients view their

(c) 2010 Huas et al; licensee BioMed Central Ltd. This is an Open Access article distributed under the terms of the Creative Commons 
own adherence to treatment and on the different patient variables that are associated with adherence.

We have recently performed a large, observational, pharmacoepidemiological study of osteoporosis and its treatment in primary and secondary care in France (POSTEPI study). The primary objective of the study was to describe the characteristics of women receiving treatment for osteoporosis diagnosed in the previous six months. Secondary objectives were to identify variables potentially associated with different treatment regimens, to assess impact on quality of life, and to evaluate patient adherence to, and satisfaction with, their antiosteoporosis treatment. The treatment data will be presented elsewhere. This article reports the data on adherence and patient satisfaction.

\section{Methods}

This was an observational, cross-sectional pharmacoepidemiological study performed in France between November 2007 and March 2008.

\section{Participating physicians}

General practitioners (GPs), gynaecologists and rheumatologists participated in the study. These were selected at random from a national physician list (CEGEDIM database) using a sampling method stratified by region. The planned number of participating physician was 650 .

\section{Subjects}

Participants included all women in whom bone densitometry had been performed or who had experienced a fracture not related to trauma or cancer in the previous six months in a patient registry. Of these, the first three post-menopausal women in whom a diagnosis of osteoporosis had been made on the basis of low bone mass density or fracture occurrence in the previous six months, and for whom osteoporosis treatment was initiated, constituted, the questionnaire population. Exclusion criteria included participation in studies likely to have influenced treatment and illiteracy.

\section{Data collection}

Participating physicians provided general professional information and specific information on osteoporosis management. For each patient included in the registry, the physician noted the age of the patient, the age at menopause, the age at which osteoporosis was diagnosed, information on densitometry, fractures, fracture risk factors and any current or planned osteoporosis treatments. For the questionnaire population, each participating physician completed a medical questionnaire. This included items on height, weight, exercise, fracture history, osteoporosis management, comorbidities, and comedication. In addition, the physician provided patients with a questionnaire to complete. This collected data on sociodemographic features, lifestyle, attitudes and knowledge concerning osteoporosis and its treatment, treatment compliance, treatment satisfaction and quality of life. Information on compliance was collected both from physicians and from patients. Physicians were asked whether they considered their patients to be fully compliant. Treatment compliance from the patient point of view was evaluated with the French version of Morisky Medication-taking Adherence Scale (MMAS) (Additional file 1) [6] and quality of life with the SF-12 health profile measure, both completed by the patient. Both were used in their validated French translations. Treatment satisfaction was assessed by asking the patient if she was satisfied with her osteoporosis treatment. Five response modalities were possible. For the purposes of the analysis, replies were grouped into three classes (very/rather unsatisfied, neither satisfied nor dissatisfied, or very/quite satisfied). Patients were also asked whether they considered their treatment regimen to be adapted to their lifestyle and whether they considered the frequency of administration of their treatment regimen to be easy to maintain over the long term. The completed questionnaire was returned directly to the data management centre.

The MMAS contains four items to which a yes or no reply is given (Additional file 2). These questions are 'Do you ever forget to take your [osteoporosis] medicine?', 'Do you ever have problems remembering to take your [osteoporosis] medication?', 'When you feel better, do you sometimes stop taking your [osteoporosis] medicine? and 'Sometimes, if you feel worse when you take your [osteoporosis] medicine, do you stop taking it?'. Each 'no' reply is scored as one and each 'yes' reply is scored as zero, allowing a total possible score ranging from zero (worst compliance) to four (full compliance). A patient was considered non-compliant to treatment if her score on the MMAS was less than four.

\section{Statistical analysis}

The present analysis was restricted to those patients in whom a treatment had been initiated during the previous six months. Statistical comparisons were performed using the $\chi^{2}$ test or Fisher's exact test for categorical variables and analysis of variance or the Wilcoxon test for quantitative variables. All tests were two-tailed. A probability threshold of 0.05 was taken as statistically significant. Variables associated with compliance were evaluated by multivariate logistic regression analysis using a rising stepwise procedure with a cut-off probability threshold of 0.1 at each step. The variables entered into this analysis corresponded to all those collected in the case report form whose frequencies differed between compliant and non-compliant patients at 
a probability level of 0.2 in univariate analysis. A final multivariate model was generated in which only variables retained in the stepwise model were entered in order to generate odds ratios for the association with compliance. Data were analysed using $\mathrm{SAS}^{\oplus}$ software, Version 8.2 (SAS, Cary, USA) on Windows.

\section{Ethics}

The survey protocol was submitted for evaluation to the CCTIRS (National Ethics Advisory Board). They considered that participation of patients in the study would not affect their medical care, and therefore that it was not necessary to obtain formal Ethics Committee approval nor to collect signed informed consent from each patient. The only requirement stipulated was that formal information on the goals and methods of the study be provided for each patient. Procedures for data collection and management were approved by the Conseil National de l'Informatique et des Libertés (CNIL), which ensures that all medical information is kept confidential and anonymous.

\section{Results}

\section{Participating physicians}

Overall, 684 physicians included patients in the registry, namely 420 GPs, 154 rheumatologists and 110 gynaecologists.

\section{Subjects}

The first three registry patients included per investigator ( $n=1,306)$ were entered into the questionnaire study and proposed an autoquestionnaire. Completed autoquestionnaires were received from 1,217 women (93.2\%), who constituted the autoquestionnaire population. The analysis reported here is restricted to the 785 women who had already been prescribed a treatment at the time of the consultation. For the remaining 521 women, treatment was initiated during the consultation and compliance thus could not be assessed.

Patient characteristics and treatment are presented in Table 1.

\section{Compliance}

The physicians considered their patients to be fully compliant in almost all cases (Table 2). From the patients' perspective, $65.5 \%$ of women considered themselves to be fully compliant (MMAS score $=4$ ), and the correlation between patient and physician perceptions of compliance was very poor ( $p=<0.001$; MacNemar test; $\kappa$ coefficient $=0.11$ [95\% CI: 0.06 to 0.16$]$ ). Nonetheless, patients who rated themselves as fully compliant were more likely to be considered compliant by their physicians and vice versa $(p<0.01$ : Cochran-Mantel Haenszel test; Table 2). Patient-rated compliance differed between the different treatments ( $\mathrm{p}<0.001$; Figure 1), being highest for monthly bisphosphonates (79.7\%) and lowest for hormone substitution therapy (50.0\%).

\section{Satisfaction}

Data on treatment satisfaction is presented in Table 3. The rate of treatment satisfaction varied with the frequency of administration ( $p=0.001 ; \chi^{2}$ test), being highest with monthly treatments. Satisfaction did not however, differ between the different classes of medication ( $p=0.05 ; \chi^{2}$ test; data not shown).

\section{Variables associated with compliance}

In a first step, all variables collected during the course of the study were evaluated for their potential association with patient-reported compliance (MMAS score $=4$ compared to score $<4$ ) using univariate analysis. Variables related to attitudes to disease and treatment identified on the autoquestionnaire are listed in Table 4. After a stepwise multivariate regression analysis, six variables were retained and corresponding odds ratios generated (Table 5), namely frequency of treatment administration, whether the patient considered the frequency of treatment administration to be adapted to long-term treatment, whether she considered that her osteoporosis could have consequences for her health, whether she considered herself well-informed about osteoporosis, whether she walked for at least twenty minutes each day and the mental component score of the SF-12.

Table 1 Characteristics of women treated for osteoporosis at the time of the consultation (questionnaire population; $\mathbf{N}=785$ ).

\begin{tabular}{llll}
\hline Patient characteristics & \multicolumn{3}{l}{ Treatments } \\
\hline Age (years) & $66.30 \pm 9.07$ & Daily bisphosphonates & $17(2.2 \%)$ \\
Age at menopause (years) & $49.75 \pm 3.97$ & Weekly bisphosphonates & $305(40.6 \%)$ \\
Time since menopause (years) & $16.49 \pm 9.38$ & Monthly bisphosphonates & $202(26.9 \%)$ \\
Densitometry in the last six months & $667(85.3 \%)$ & SERMs & $76(10.1 \%)$ \\
Osteoporotic fractures & $389(51.7 \%)$ & Strontium ranelate & $119(15.8 \%)$ \\
At least one risk factor & $618(78.7 \%)$ & Others & $26(3.5 \%)$ \\
\hline
\end{tabular}

Data are presented as mean \pm SD for quantitative variables and as numbers of women (\%) for categorical variables. Data were missing for up to six patients for certain variables. SERM: selective oestrogen receptor modulators. 'Others' include parathyroid hormone analogues and hormone substitution therapy. 
Table 2 Compliance with treatment as rated by the physician and patient.

\begin{tabular}{ll}
\hline Physician-rated compliance & TOTAL \\
Patients considered compliant & 748 (95.4\%) \\
\hline Patient-rated compliance & $3.34 \pm 1.07$ \\
MMAS score (mean \pm SD) & $483(65.5 \%)$ \\
Compliant patients (Morisky score = 4) & 476 (64.6\%) \\
\hline Concordance & $26(3.5 \%)$ \\
Patients considered compliant by both physician and patient & $0.11[95 \%$ Cl: 0.06 to 0.16$]$ \\
Patients considered non-compliant by both physician and patient & Kappa concordance coefficient
\end{tabular}

Significant differences in reply distributions were not observed between the three physician groups. Data for physician-reported compliance concern the questionnaire population ( $\mathrm{N}=785$; missing data: $\mathrm{N}=1$ ) and for patient-rated compliance and concordance the autoquestionnaire population $(\mathrm{N}=751$; missing data: $N=13$ ). MMAS: Morisky Medication-taking Adherence Scale.

\section{Discussion}

In this study, we observed a large discrepancy between treatment compliance as evaluated by the investigator and as considered by the patient. Although the physicians thought that compliance was adequate for over $95 \%$ of women, only two-thirds of the patients rated themselves as fully compliant.
Compliance rates (as defined by the patient) differed between medication groups, being highest for bisphosphonates and lowest for HRT and strontium ranelate. Given the very small number of women taking HRT, the precision of the compliance rate for this treatment should be regarded as limited. Among the bisphosphonates, significant differences in compliance were

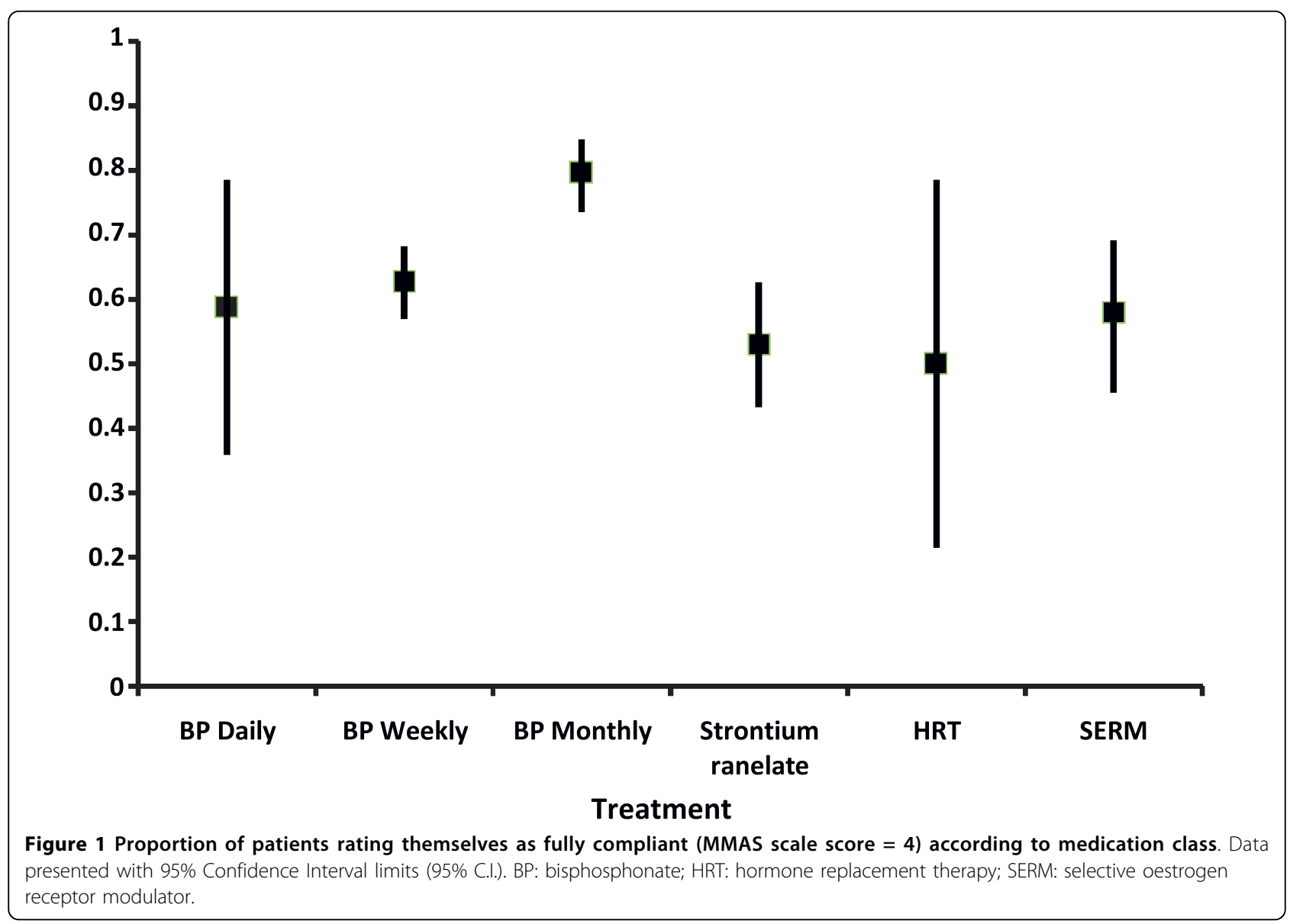


Table 3 Treatment satisfaction as a function of frequency of administration (all treatments combined).

\begin{tabular}{|c|c|c|c|c|}
\hline & Daily & Weekly & Monthly & TOTAL \\
\hline \multicolumn{4}{|c|}{ Patient satisfaction regarding osteoporosis treatment } & $p \leq 0.001$ \\
\hline Very unsatisfied or rather unsatisfied & $4(2 \%)$ & $5(8 \%)$ & $1(4 \%)$ & $10(13.8 \%)$ \\
\hline Neither satisfied nor dissatisfied & $081(38.9 \%)$ & $119(41.2 \%)$ & $069(30.5 \%)$ & $269(37.2 \%)$ \\
\hline Quite satisfied or very satisfied & $123(59.1 \%)$ & 165 (57.1\%) & $156(69.0 \%)$ & $444(61.4 \%)$ \\
\hline \multicolumn{5}{|c|}{ Treatment regimen considered adapted to lifestyle } \\
\hline & $188(89.5 \%)$ & $279(97.2 \%)$ & $226(99.6 \%)$ & $p \leq 0.001$ \\
\hline \multicolumn{5}{|c|}{ Frequency of treatment administration considered easy to maintain over the long-term } \\
\hline & $170(81.3 \%)$ & $262(91.3 \%)$ & $218(96.5 \%)$ & $p \leq 0.001$ \\
\hline
\end{tabular}

Data were missing for up to three patients for certain variables.

observed between the various treatment regimens, being highest for monthly preparations and lowest for daily regimens. Indeed, in the multivariate regression analysis, treatment administration frequency was the variable with the strongest association with compliance, with an increased probability of being compliant to a monthly treatment over twofold higher than for a daily treatment. Other variables associated with improved compliance were the patient's view of the consequences of osteoporosis, knowledge about osteoporosis, walking over twenty minutes a day, and a higher mental component quality of life score. Somewhat surprisingly, previous fracture experience did not influence compliance.
It will be important to validate whether these determinants of compliance can be reproduced in prospective longitudinal studies of the treatment of osteoporosis.

Around sixty percent of women reported being quite or very satisfied with their treatment, and a similar proportion considered following their treatment to be a priority for their health. Treatment satisfaction was also higher in women receiving a monthly treatment than a weekly treatment, and in those receiving a weekly treatment compared to a daily one.

The study has a number of strengths and limitations. The strengths include the relatively large sample size, the sampling method, which should ensure representativity

Table 4 Autoquestionnaire variables independently associated with compliance identified by univariate regression analysis.

\begin{tabular}{|c|c|c|c|c|}
\hline Variable & Response modality & $\begin{array}{l}\text { Non-compliant } \\
\mathrm{N}=255\end{array}$ & $\begin{array}{l}\text { Compliant } \\
\mathrm{N}=483\end{array}$ & $p$ \\
\hline Osteoporosis considered as an illness & Yes & $172(67.1 \%)$ & $378(79.1 \%)$ & 0.001 \\
\hline Consequences of osteoporosis according to the patient & $\begin{array}{l}\text { Serious } \\
\text { Quite serious } \\
\text { Not serious }\end{array}$ & $\begin{array}{l}62(24.3 \%) \\
150(58.8 \%) \\
43(16.9 \%)\end{array}$ & $\begin{array}{l}198(41.3 \%) \\
244(50.8 \%) \\
81(11.0 \%)\end{array}$ & $\leq 0.001$ \\
\hline Known osteoporotic risk factors before diagnosis & Yes & $43(16.9 \%)$ & $143(29.6 \%)$ & $\leq 0.001$ \\
\hline Well Informed on osteoporosis since diagnosis & $\begin{array}{l}\text { Strongly agree } \\
\text { Agree } \\
\text { Disagree } \\
\text { Strongly disagree }\end{array}$ & $\begin{array}{l}41(16.1 \%) \\
46(18.1 \%) \\
164(64.6 \%) \\
3(1.2 \%)\end{array}$ & $\begin{array}{l}170(35.2 \%) \\
37(7.7 \%) \\
274(56.7 \%) \\
2(0.4 \%) \\
\end{array}$ & $\leq 0.001$ \\
\hline Osteoporosis treatment considered as a priority & $\begin{array}{l}\text { Strongly agree } \\
\text { Agree } \\
\text { Disagree } \\
\text { Strongly disagree }\end{array}$ & $\begin{array}{l}69(27.1 \%) \\
37(14.5 \%) \\
144(56.5 \%) \\
5(2.0 \%) \\
\end{array}$ & $\begin{array}{l}228(47.3 \%) \\
35(7.3 \%) \\
216(44.8 \%) \\
3(0.6 \%) \\
\end{array}$ & $\leq 0.001$ \\
\hline Patients perspective: possible & $\begin{array}{l}\text { Less than } 3 \text { months } \\
3 \text { months to } 1 \text { year } \\
1 \text { to } 3 \text { years } \\
\text { More than } 3 \text { years }\end{array}$ & $\begin{array}{l}1(0.4 \%) \\
9(3.7 \%) \\
68(27.9 \%) \\
166(68.0 \%)\end{array}$ & $\begin{array}{l}0(0.0 \%) \\
4(0.8 \%) \\
96(20.1 \%) \\
377(79.0 \%)\end{array}$ & $\leq 0.001$ \\
\hline Walking over 20 min per day & Yes & $128(50.2 \%)$ & $312(65.0 \%)$ & $\leq 0.001$ \\
\hline Physical component score of SF12 (PCS) & Score unit & $44.50 \pm 7.66$ & $45.85 \pm 8.06$ & 0.041 \\
\hline Mental component score of SF12 (MCS) & Score unit & $43.16 \pm 9.78$ & $46.03 \pm 10.06$ & $\leq 0.001$ \\
\hline Satisfied by osteoporosis treatment & $\begin{array}{l}\text { Very/rather unsatisfied } \\
\text { Neither satisfied nor unsatisfied } \\
\text { Very/quite satisfied }\end{array}$ & $\begin{array}{l}6(2.4 \%) \\
130(51.2 \%) \\
1180(46.4 \%)\end{array}$ & $\begin{array}{l}4(0.8 \%) \\
141(29.6 \%) \\
331(69.5 \%)\end{array}$ & $\leq 0.001$ \\
\hline Treatment regimen adapted to your lifestyle & Yes & $235(92.5 \%)$ & $468(97.5 \%)$ & 0.003 \\
\hline Treatment regimen difficult to follow for a long-time & No & $201(79.8 \%)$ & $461(96.0 \%)$ & $\leq 0.001$ \\
\hline
\end{tabular}


Table 5 Odds ratios variables independently associated with compliance identified by multivariate regression analysis (odds ratios presented with their $95 \%$ confidence intervals).

\begin{tabular}{|c|c|c|c|}
\hline Effect & Response & Odds Ratio & $p$ \\
\hline \multirow[t]{2}{*}{ Frequency of administration adapted to long-term treatment } & No & 1.00 & \\
\hline & Yes & $4.227[2.272 ; 7.863]$ & $<0.0001$ \\
\hline \multirow[t]{3}{*}{ Frequency of treatment administration } & Daily & 1.00 & . \\
\hline & Weekly & $1.273[0.836 ; 1.938]$ & 0.2607 \\
\hline & Monthly & $2.232[1.367 ; 3.643]$ & 0.0013 \\
\hline \multirow[t]{3}{*}{ Consequences of osteoporosis according to the patient } & Serious & 1.00 & \\
\hline & Quite serious & $0.617[0.407 ; 0.937]$ & 0.0234 \\
\hline & Not serious & $0.466[0.250 ; 0.868]$ & 0.0161 \\
\hline \multirow[t]{3}{*}{ Well Informed on osteoporosis since diagnosis } & Strongly agree & 1.00 & . \\
\hline & Weakly agree & $0.564[0.358 ; 0.889]$ & 0.0006 \\
\hline & Disagree & $0.322[0.169 ; 0.616]$ & 0.0136 \\
\hline \multirow[t]{2}{*}{ Walking over 20 minutes a day } & No & 1.00 & \\
\hline & Yes & $1.496[1.031 ; 2.171]$ & 0.0341 \\
\hline Mental component score of SF12 & One point increment & $1.021[1.002 ; 1.040]$ & 0.0328 \\
\hline
\end{tabular}

of women consulting for osteoporosis in primary and secondary care in France, the relatively high response rate, and the collection of data directly from the patients. The principal limitation relates to the choice of the instrument for determining compliance to treatment. The use of a patient-completed questionnaire is appropriate for a naturalistic study such as this, but relies on the accuracy of patient self-report, which cannot be independently controlled. This potential source of bias is compounded by the fact that the data were collected retrospectively. The use of a more objective measure, such as pill count, may have provided more accurate data but could have introduced a significant uncontrolled bias in that implementation of the measure may have modified the compliance behaviour that it was set up to report. The MMAS [6] was originally developed to assess compliance to medication use in patients with essential hypertension, but has subsequently been used successfully in other fields of medicine in which adherence is a particular issue, including asthma, HIV, diabetes mellitus and bipolar disorder. In addition, the interpretation of the magnitude of difference between physician- and patient-rated compliance should be tempered by the fact that the instruments used to collect this information were different. In addition, it is clear that other potential determinants of compliance may exist, on which data were not collected in this study. These include patient preference for different treatments and participation in the choice of treatment. Finally, the fact that participation in the study by physicians was voluntary may introduce bias if these are not representative of the French physician population, for example with respect to providing information on treatments to their patients.

Poor discernment by physicians of their patients' subjective view of their medical condition has been demonstrated previously for health outcomes, such as health-related quality of life [7], treatment tolerability [8] or functional disability [9]. With regard to adherence, differences in physician- and patient-perceived compliance such as those described here have been reported previously in many other areas of medicine, notably in psychiatry $[10,11]$. Similarly, a previous study has shown that physicians did not correctly estimate patient-reported compliance to HIV therapy in 35\% of patients [12].

The differences observed in compliance between treatment classes is also consistent with a number of previous studies [13-15], as is the association between compliance and poor quality of life [16]. A relationship between frequency of treatment administration and treatment preference has previously been reported in the two BALTO studies, which used a randomised, cross-over design to compare a monthly and a weekly formulation of bisphosphonates [17].

A recent study reported that many individuals who suffered from a fragility fracture did not associate their fracture with osteoporosis and speculated that there may be a relationship between risk perception and adherence to therapy [18]. Our findings showed that patients in the non-compliant group were characterised by less appropriate perceptions of disease status and less knowledge about risk factors and consequences of osteoporosis. Similarly, not considering osteoporosis to be a serious disease was another factor associated with non-compliance.

The findings of this study have several implications. Firstly, they emphasise the importance of collecting data on adherence directly from the patient, rather than from the physician. Secondly, our results showed that patients who considered themselves poorly informed about their 
disease reported poor compliance. In a recent Canadian study, osteoporotic women claimed that their healthcare providers did not always give them enough information about medications or gave them information in a format that was difficult to understand. In this study, the absence of a satisfactory exchange of information between physicians and patients was identified as a major determinant of adherence [19]. One of the most effective approaches for improving medication adherence may thus be to encourage more open, co-operative relationships that lead to concordance between the physician and patient [20].

Women who walked over twenty minutes a day also reported better compliance than those who did not, perhaps because they attach more importance to keeping well and taking control of their health in general. The behaviour of such patients who take an active role in managing lifestyle patterns that have an impact on their disease has previously been described in the field of type 2 diabetes [21], where these 'Disease Managers' tend to show high treatment adherence rates.

The observed association between compliance and patient beliefs and attitudes with respect to osteoporosis reinforces the interest of patient education measures following diagnosis for all women with post-menopausal osteoporosis. Understanding patients' health beliefs better and re-orientating these when they are inaccurate may thus be a useful key to improve compliance [22]. Medication beliefs have indeed been shown elsewhere to be more powerful predictors of reported adherence than clinical and socio-demographic factors [23]. The authors of the latter study proposed that many patients engaged in an implicit cost-benefit analysis in which beliefs about the necessity of their medication are weighed against concerns about the potential adverse effects of taking it, and that these beliefs influenced medication adherence.

Methods to assess adherence are multiple and very different from each other and that, even in the single field. In the osteoporosis literature[24], reported methods based on the care provider (eg, pill count, physical examination for frequent clinical adverse effects), patients (patients' self-report [eg, written or electronic diary], elicited report [eg, global or specific questioning], or other methods), use of devices (eg, pill count by electronic monitoring), biologic elements (eg, serum levels, urine levels, measurement of expected biologic effects), or other methods. Pharmacy data give one measure of adherence whose main advantages are sample size and being almost exempt from selection bias. However, principal well-known limit of pharmacy database is absence of information about patients' behaviors with tablets at their home (omission, drug holiday etc.). In this study, MMAS questionnaire took into account those behavioural aspects as an informative and complementary measure. Thus, our results showing better compliance with monthly regimen are consistent with recent ones on French prescription database [25].

\section{Conclusions}

The POSTEPI study confirmed that compliance to antiosteoporosis treatments as considered by the patient is poor, but identified reduction of the dosing regimen frequency and patient education measures as potentially useful ways of improving compliance.

\section{Additional material}

Additional file 1: French version of Morisky Medication-taking

Adherence Scale (MMAS) - 4 items. Linguistic validation by Mapi

Research Institute consisted in forward, backward translation, clinician's review and patients' cognitive debriefing.

Additional file 2: US original version of Morisky Medication-taking Adherence Scale (MMAS) - 4 items.

\section{Acknowledgements}

The authors would like to express their gratitude to all the physicians who accepted to participate in the study and provided data. Editorial support for the preparation of this manuscript was provided by Adam Doble and Isabelle Gauthier, Foxymed SARL, Paris, France.

This study was funded by GSK and Laboratoire Roche, purveyors of ibandronate, an osteoporosis treatment.

\section{Author details}

${ }^{1}$ Department of General Practice, UFR Paris 7, Paris, France. ${ }^{2}$ Rheumatology Department, Poitiers University Hospital, Poitiers, France. ${ }^{3}$ Rheumatology Department, Montpellier University Hospital, Montpellier, France. ${ }^{4}$ Rheumatology Department, Roger Salengro Hospital, Lille, France. ${ }^{5}$ STAT-Process, Port-Mort, France. ${ }^{6}$ Nukléus, Paris, France. ${ }^{7}$ Laboratoire GlaxoSmithKline, Marly le Roi, France. ${ }^{8}$ CERMES, IFR69, INSERM U750, National Institute of Health and Medical Research, Villejuif, France.

\section{Authors' contributions}

$\mathrm{BC}, \mathrm{FB}, \mathrm{FD}$ and $\mathrm{DH}$ made up the academic steering committee of the study. They advised on the study design, contributed to the analysis of the data and interpretation of the results, recommended the publication policy to follow and contributed to writing and critical revision of the manuscript. FM performed the data management and analysis for the study. CR and VB were responsible for the day-to-day operational management of the study. AFG and FEC conceived the study, recruited the steering committee, oversaw the implementation of the study, and initiated the preparation of the present manuscript. And finally, all authors read and approved the final manuscript.

\section{Competing interests}

AFG and FEC are employees of Laboratoires GlaxoSmithKline (GSK), France who markets ibandronate and denosumab, two anti-osteoporosis treatments. BC has received consultancy fees from GSK, Laboratoires Roche, Amgen, Novartis and Merck, Sharpe \& Dohme with respect to his participation in this and other projects concerning the treatment of osteoporosis. FB, FD and DH have received consultancy fees from GSK and Laboratoire Roche with respect to their participation in this and other projects concerning osteoporosis. FM, CR and VB received stipends from GSK for data analysis (FM) or for coordination of the study (CR and VB).

Received: 25 January 2010 Accepted: 20 August 2010

Published: 20 August 2010 


\section{References}

1. Geusens PP, Roux CH, Reid DM, Lems WF, Adami S, Adachi JD, Sambrook PN, Saag KG, Lane NE, Hochberg MC: Drug Insight: choosing a drug treatment strategy for women with osteoporosis-an evidencebased clinical perspective. Nat Clin Pract Rheumatol 2008, 4(5):240-248.

2. Tosteson AN, Grove MR, Hammond CS, Moncur MM, Ray GT, Hebert GM, Pressman AR, Ettinger B: Early discontinuation of treatment for osteoporosis. Am J Med 2003, 115(3):209-216.

3. Caro JJ, Ishak KJ, Huybrechts KF, Raggio G, Naujoks C: The impact of compliance with osteoporosis therapy on fracture rates in actual practice. Osteoporos Int 2004, 15(12):1003-1008.

4. Cotte FE, Mercier F, De Pouvourville G: Relationship between compliance and persistence with osteoporosis medications and fracture risk in primary health care in France: a retrospective case-control analysis. Clinical therapeutics 2008, 30(12):2410-2422.

5. Cortet B, Benichou O: Adherence, persistence, concordance: do we provide optimal management to our patients with osteoporosis? Joint Bone Spine 2006, 73(5):e1-7.

6. Morisky DE, Green LW, Levine DM: Concurrent and predictive validity of a self-reported measure of medication adherence. Med Care 1986, 24(1):67-74.

7. Sprangers MA, Aaronson NK: The role of health care providers and significant others in evaluating the quality of life of patients with chronic disease: a review. Journal of clinical epidemiology 1992, 45(7):743-760

8. Macquart-Moulin G, Viens P, Bouscary ML, Genre D, Resbeut M, Gravis G, Camerlo J, Maraninchi D, Moatti JP: Discordance between physicians' estimations and breast cancer patients' self-assessment of side-effects of chemotherapy: an issue for quality of care. British journal of cancer 1997, 76(12):1640-1645.

9. Hidding A, van Santen M, De Klerk E, Gielen X, Boers M, Geenen R, Vlaeyen J, Kester A, van der Linden S: Comparison between self-report measures and clinical observations of functional disability in ankylosing spondylitis, rheumatoid arthritis and fibromyalgia. The Journal of rheumatology 1994, 21(5):818-823.

10. Byerly MJ, Thompson A, Carmody T, Bugno R, Erwin T, Kashner M, Rush AJ: Validity of electronically monitored medication adherence and conventional adherence measures in schizophrenia. Psychiatric services (Washington, DC) 2007, 58(6):844-847.

11. Velligan DI, Wang M, Diamond P, Glahn DC, Castillo D, Bendle S, Lam YW Ereshefsky L, Miller AL: Relationships among subjective and objective measures of adherence to oral antipsychotic medications. Psychiatric services (Washington, DC) 2007, 58(9):1187-1192.

12. Murri R, Ammassari A, Trotta MP, De Luca A, Melzi S, Minardi C, Zaccarelli M, Rellecati P, Santopadre P, Soscia F, et al: Patient-reported and physician-estimated adherence to HAART: social and clinic centerrelated factors are associated with discordance. Journal of general internal medicine 2004, 19(11):1104-1110.

13. Cramer JA, Amonkar MM, Hebborn A, Altman R: Compliance and persistence with bisphosphonate dosing regimens among women with postmenopausal osteoporosis. Curr Med Res Opin 2005, 21(9):1453-1460.

14. Cramer JA, Lynch NO, Gaudin AF, Walker M, Cowell W: The effect of dosing frequency on compliance and persistence with bisphosphonate therapy in postmenopausal women: a comparison of studies in the United States, the United Kingdom, and France. Clin Ther 2006 28(10):1686-1694.

15. Recker RR, Gallagher R, MacCosbe PE: Effect of dosing frequency on bisphosphonate medication adherence in a large longitudinal cohort of women. Mayo Clin Proc 2005, 80(7):856-861.

16. Cote I, Farris K, Feeny D: Is adherence to drug treatment correlated with health-related quality of life? Qual Life Res 2003, 12(6):621-633.

17. Hadji P, Minne H, Pfeifer M, Bourgeois P, Fardellone P, Licata A, Devas V, Masanauskaite D, Barrett-Connor E: Treatment preference for monthly oral ibandronate and weekly oral alendronate in women with postmenopausal osteoporosis: A randomized, crossover study (BALTO II). Joint Bone Spine 2008, 75(3):303-310.

18. Giangregorio L, Papaioannou A, Thabane L, DeBeer J, Cranney A, Dolovich L, Adili A, Adachi JD: Do patients perceive a link between a fragility fracture and osteoporosis? BMC musculoskeletal disorders 2008 9:38.
19. Lau E, Papaioannou A, Dolovich L, Adachi J, Sawka AM, Burns S, Nair K, Pathak A: Patients' adherence to osteoporosis therapy: exploring the perceptions of postmenopausal women. Canadian family physician Medecin de famille canadien 2008, 54(3):394-402.

20. Donovan $J \mathrm{~L}$, Blake DR: Patient non-compliance: deviance or reasoned decision-making? Social science \& medicine (1982) 1992, 34(5):507-513.

21. Veg A, Rosenqvist U, Sarkadi A: Self-management profiles and metabolic outcomes in type 2 diabetes. Journal of advanced nursing 2006, 56(1):44-54.

22. Veazie PJ, Cai S: A connection between medication adherence, patient sense of uniqueness, and the personalization of information. Medical hypotheses 2007, 68(2):335-342.

23. Horne R, Weinman J: Patients' beliefs about prescribed medicines and their role in adherence to treatment in chronic physical illness. Journal of psychosomatic research 1999, 47(6):555-567.

24. Gossec L, Tubach F, Dougados M, Ravaud P: Reporting of adherence to medication in recent randomized controlled trials of 6 chronic diseases: a systematic literature review. Am J Med Sci 2007, 334(4):248-254.

25. Cotté FE, Fardellone P, Mercier F, Gaudin AF, Roux C: Adherence to monthly and weekly oral bisphosphonates in women with osteoporosis. Osteoporos Int 2010, 21(1):145-155.

Pre-publication history

The pre-publication history for this paper can be accessed here: http://www.biomedcentral.com/1472-6874/10/26/prepub

doi:10.1186/1472-6874-10-26

Cite this article as: Huas et al:: Compliance and treatment satisfaction of post menopausal women treated for osteoporosis. Compliance with osteoporosis treatment. BMC Women's Health 2010 10:26.

\section{Submit your next manuscript to BioMed Central and take full advantage of:}

- Convenient online submission

- Thorough peer review

- No space constraints or color figure charges

- Immediate publication on acceptance

- Inclusion in PubMed, CAS, Scopus and Google Scholar

- Research which is freely available for redistribution

Submit your manuscript a www.biomedcentral.com/submit
Biomed Central 